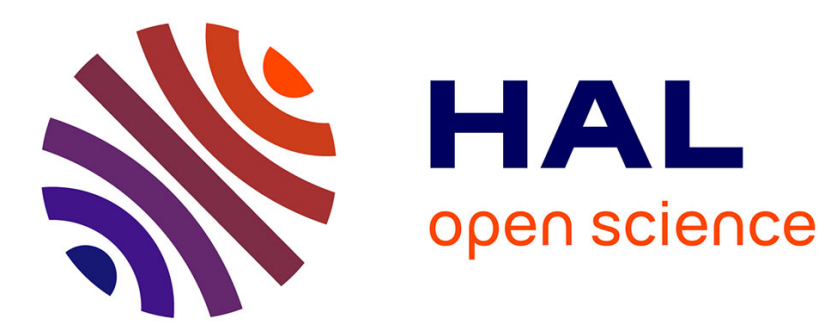

\title{
Band or Point Inflation Targeting? An Experimental Approach
}

\author{
Camille Cornand, Cheick Kader M'Baye
}

\section{To cite this version:}

Camille Cornand, Cheick Kader M'Baye. Band or Point Inflation Targeting? An Experimental Approach. 2016. halshs-01313095

\section{HAL Id: halshs-01313095 \\ https://shs.hal.science/halshs-01313095}

Preprint submitted on 9 May 2016

HAL is a multi-disciplinary open access archive for the deposit and dissemination of scientific research documents, whether they are published or not. The documents may come from teaching and research institutions in France or abroad, or from public or private research centers.
L'archive ouverte pluridisciplinaire $\mathbf{H A L}$, est destinée au dépôt et à la diffusion de documents scientifiques de niveau recherche, publiés ou non, émanant des établissements d'enseignement et de recherche français ou étrangers, des laboratoires publics ou privés. 


\title{
GATE

UMR 5824

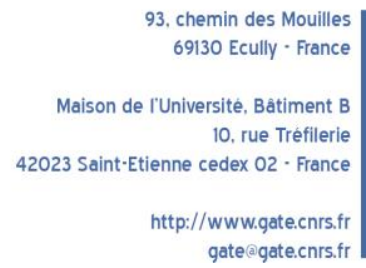

WP 1616 - May 2016

\section{Band or Point Inflation Targeting? An Experimental Approach}

\author{
Camille Cornand, Cheick Kader M'baye
}

\begin{abstract}
:
We conduct laboratory experiments with human subjects to test the rationale of adopting a band versus point inflation targeting regime. Within the standard New Keynesian model, we evaluate the macroeconomic performances of both regimes according to the strength of shocks affecting the economy. We find that when the economy faces small shocks, the average level of inflation as well as its volatility are significantly lower in a band targeting regime, while the output gap and interest rate levels and volatility are significantly lower in a point targeting regime with tolerance bands. However, when the economy faces large shocks, choosing the suitable inflation targeting regime is irrelevant because both regimes lead to comparable performances. These findings stand in contrast to those of the literature and question the relevance of clarifying a mid-point target within the bands, especially in emerging market economies more inclined to large and frequent shocks.
\end{abstract}

\section{Keywords:}

Band inflation target; point inflation target; inflation expectations; monetary policy; New Keynesian model; macroeconomic shocks; laboratory experiments

JEL codes:

E58, E52, C91, C92

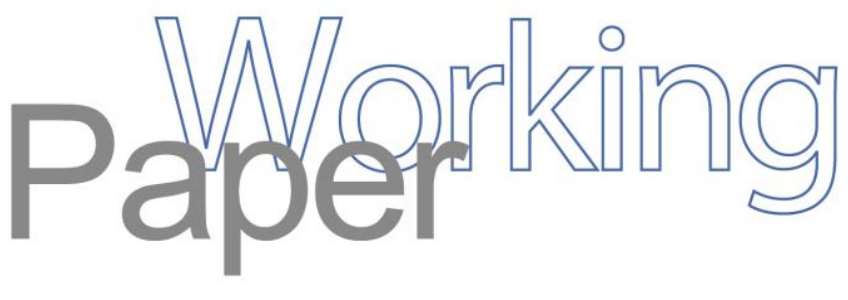




\title{
Band or Point Inflation Targeting? An Experimental Approach*
}

\author{
Camille Cornand ${ }^{\dagger}$ \\ Cheick Kader M’baye
}

May 2, 2016

\begin{abstract}
We conduct laboratory experiments with human subjects to test the rationale of adopting a band versus point inflation targeting regime. Within the standard New Keynesian model, we evaluate the macroeconomic performances of both regimes according to the strength of shocks affecting the economy. We find that when the economy faces small shocks, the average level of inflation as well as its volatility are significantly lower in a band targeting regime, while the output gap and interest rate levels and volatility are significantly lower in a point targeting regime with tolerance bands. However, when the economy faces large shocks, choosing the suitable inflation targeting regime is irrelevant because both regimes lead to comparable performances. These findings stand in contrast to those of the literature and question the relevance of clarifying a mid-point target within the bands, especially in emerging market economies more inclined to large and frequent shocks.
\end{abstract}

Keywords: band inflation target; point inflation target; inflation expectations; monetary policy; New Keynesian model; macroeconomic shocks; laboratory experiments.

JEL Classification: E58; E52; C91; C92.

\footnotetext{
${ }^{*}$ We are thankful to the ANR-DFG joint grant for financial support (ANR-12-FRAL-0013-01 StabEX). This research was performed within the framework of the LABEX CORTEX (ANR-11-IDEX-007) operated by the French National Research Agency (ANR).

${ }^{\dagger}$ Univ Lyon, CNRS, GATE L-SE UMR 5824, F-69130 Ecully, France. Email: cornand@gate.cnrs.fr.

${ }^{\ddagger}$ University of Bamako, Bamako, Mali. Email: cheick_mbaye2004@yahoo.fr.
} 


\section{Introduction}

Inflation targeting (IT) regimes are generally associated with higher macroeconomic performances compared to other monetary regimes. ${ }^{1}$ In an IT regime, the central bank is attributed a clear mandate to pursue inflation stabilization as the primary objective of monetary policy. To this aim, a target for inflation is explicitely announced to the public. However, there is still a debate about whether a central bank should explicitely announce a numerical point or band target for inflation to the public. This paper precisely aims at contributing to this debate by experimentally investigating how point and band inflation targets perform in terms of macroeconomic performances.

The debate related to band versus point IT focuses on the advantages and drawbacks of each regime. The main argument in favor of the adoption of a band IT regime is that the band can signal to the public that the central bank may fail to achieve its numerical objective in a context of uncertainty. Several countries have adopted such a IT strategy (New Zealand, Canada), providing letters of explanations and the Governors of central banks can even be given penalties as soon as actual inflation deviates from the band target. ${ }^{2}$ Mishkin and Westelius (2008) analyze the behavior of band IT in a Barro and Gordon (1983) framework, in which time inconsistency is not the result of central bank's preferences, but of the government's pressure. They find that the band IT regime better overcomes time inconsistency. They also show that in an environment characterized by uncertainty about economic fundamentals, the bandwidth is highly crucial to avoid too large deviations of actual inflation from the band. The higher the uncertainty on inflation expectations, the wider the band must be to avoid too large a deviation of inflation from the target. This could explain in practice, why some emerging countries that experience more uncertainty on inflation expectations, tend to choose a large band target. Other arguments in favor of band rather than point IT are provided by Heenan et al. (2006) and Hammond (2012). First, a band target more realistically indicates what the central bank can expect to achieve regarding its inflation forecasts. Indeed, in an uncertain environment, the central bank may not properly predict the economic fundamentals. Moreover, all price indices used to measure inflation are subject to errors. Therefore, by targeting an inflation point, the central bank could unnecessarily react to any noise in the measurement of inflation. Second, a band target can be relatively simply implemented. By contrast, the persistence of inflation, combined with uncertainty and the delay in the transmission mechanism of monetary policy imply that the central bank should be excessively active if it wants to continuously achieve a numerical target, which is not easy to implement. Third, a band target provides more flexibility to the monetary authorities to smooth short-term variations in output at the expense of a temporarily higher volatility of inflation.

However in some cases, the point target may be more effective than the band for

\footnotetext{
${ }^{1}$ See e.g. Fraga et al. (2003), Levin et al. (2004), Roger and Stone (2005), Lin and Ye (2009), and Roger (2009).

${ }^{2}$ For instance, the Governor of the Reserve Bank of New Zealand is subject to resignation as soon as actual inflation deviates from the band target without convincing explanations.
} 
anchoring inflation expectations, particularly when the central bank does not commit to reach the mid-point of the band. This is especially true for countries with large bands target as emerging countries. Bernanke et al. (1999) argue that missing a band (which may happen from time to time) may be understood by the public as a more serious policy failure than missing a point (which happens continuously and inevitably). Moreover, when a band is implemented, agents mainly focus on whether inflation is just inside or outside the band, rather than on the magnitude of the deviations from the mid-point which may lead to higher volatility of macroeconomic variables. ${ }^{3}$ Orphanides and Williams (2007) analyze the impact of announcing an explicit numerical inflation target in a model in which agents have imperfect knowledge about the structure of the economy and rely on adaptive learning to continuously update their beliefs. They find that announcing an explicit numerical target can help anchoring inflation expectations and hence, reducing the costs associated with imperfect knowledge which can lead to higher macroeconomic performance.

In practice, the majority of IT central banks and especially those which adopted IT recently have opted for a point inflation target, including point targets with tolerance bands (Hammond, 2012). Using a laboratory experiment with human subjects based on the standard New Keynesian framework, this paper aims at re-evaluating the macroeconomic performances (in terms of inflation, output gap, and interest rate stabilization and volatility) of point versus band IT. Recurring to a laboratory experiment is complementary to survey data analysis dealing with natural expectations, as it allows to directly compare the band versus point regime in distinct treatments. Indeed, the controlled environment offered by laboratory experiments enables the experimenter to observe how subjects form inflation expectations and their impact on aggregate outcomes under different regimes. To highlight the role of the announced numerical target, we consider a New Keynesian Learning-to-Forecast Experiment (LtFE) ${ }^{4}$ in which we evaluate:

- The announcement of a band or point target

The central bank implements and announces a band inflation target, and depending on the treatment, it additionally announces the targeted point. Hence, if there is any difference in terms of macroeconomic outcomes, it will solely be due to the announcement effect of the numerical point target.

- The relevance of shocks

To take into account the uncertainty issue mainly put forward to justify the adoption

\footnotetext{
${ }^{3}$ In the same vein, Meyer (2002) and Mishkin (2008) argue that a point target is more appropriate in that it provides a more precise anchor for inflation expectations of agents, and a more specific target to be achieved by monetary authorities. When a country chooses to target a band for inflation, the implications in terms of costs when inflation deviates from the band will arise, and in the absence of any explicit focal point within the band, questions arise about where the monetary authorities would like inflation to be stabilized. When the movements of actual inflation within the band do not matter for the monetary authorities, the latter become too flexible and this entails a high variability of inflation, which can be detrimental. In addition, a band target can undermine the credibility of the central bank, once actual inflation deviates from the band.

${ }^{4}$ See Hommes (2011) for an overview on LtFE.
} 
of the band target, we integrate in the analysis a difference in the strength of the shocks affecting the economy. More precisely, we consider two different treatments in this respect: in the first one, the variance of shocks is low, while in the second one, it is high.

Overall, our results indicate that when the economy is characterized by a low level of uncertainty (low variance of shocks), the average level of inflation as well as its volatility are significantly lower in a band targeting regime, while the output gap and interest rate levels and volatility are significantly lower in a point targeting regime with tolerance bands. However, when the macroeconomic environment is highly uncertain (high variance of shocks), choosing the suitable IT regime is irrelevant because both regimes lead to comparable macroeconomic performances.

The present paper is part of a growing experimental macroeconomic literature. Because of its methodology, it relates to LtFE as Pfajfar and Zakelj (2013, 2014), and Assenza et al. (2013). It also relates to macro-experiments focusing on the role of central bank communication as Cornand and M'baye (2016), Kryvtsov and Petersen (2013), Arifovic and Petersen (2015), and Mokhtarzadeh and Petersen (2016). More precisely, Cornand and M'baye (2016) analyze the role of announcing the target (by comparing explicit IT with target announcement and implicit IT without any announcement), depending on the objectives of the central bank. They show that communicating the target is only useful in terms of macroeconomic performances if the central bank both has an inflation and an output gap objective as the main role of the target is to reduce uncertainty on these objectives. In the present paper, we therefore focus on a central bank having these two objectives and characterize which kind of target (band or point) allows to achieve the highest macroeconomic performances. Arifovic and Petersen (2015) study the role of communication for developed countries to escape liquidity traps. By contrast, by considering large and frequent shocks, our focus is on emerging market economies. ${ }^{5}$ We share however the same interest in the relevance of more or less explicit communication. Indeed, Arifovic and Petersen show that explicit communication may worsen the anchoring of expectations on inflation targets. Interpreting our band target as less explicit communication (than the numerical point target), our findings go in the same direction as those of Arifovic and Petersen in the sense that for relatively low shocks, both the average level and volatility of inflation are lower in the band IT regime. In a recent paper, Mokhtarzadeh and Petersen (2016) propose a LtFE to analyze different forms of central bank communication about projections on expectations. They show that central bank communication on projections of output gap and inflation stabilizes the economy.

The rest of the paper is organized as follows. Section 2 presents the New Keynesian model underlying our experimental economy. Section 3 describes the methodology, the design of our experiment, and the theoretical predictions. Section 4 focuses on the analysis of experimental outcomes. Finally, Section 5 concludes the paper.

\footnotetext{
${ }^{5}$ Indeed, as argued by Calvo and Mishkin (2003) and Fraga et al. (2003), emerging market economies suffer from instability due to large and frequent external shocks.
} 


\section{The model}

The simplified New Keynesian underlying theoretical model of the economy that is used to design our experiment is as follows. The model is based on three equations: (1) the IS curve, (2) the New Keynesian Phillips curve, and (3) the interest rate rule of the central bank:

$$
\begin{gathered}
y_{t}=\bar{y}_{t+1}^{e}-\alpha\left(i_{t}-\bar{\pi}_{t+1}^{e}\right)+g_{t}, \\
\pi_{t}=\beta \bar{\pi}_{t+1}^{e}+\lambda y_{t}+u_{t}, \\
i_{t}=\pi^{T}+\phi_{\pi}\left(\pi_{t}-\pi^{T}\right)+\phi_{y} y_{t},
\end{gathered}
$$

where $y_{t}$ and $\bar{y}_{t+1}^{e}$ respectively represent the current and average expected output gap, $\pi_{t}$ and $\bar{\pi}_{t+1}^{e}$ respectively represent the current and average expected inflation, $i_{t}$ denotes the short-term nominal interest rate, and $\pi^{T}$ states the numerical inflation target of the central bank. The parameters $\alpha, \beta, \lambda, \phi_{\pi}$ and $\phi_{y}$ are positive, $g_{t}$ and $u_{t}$ respectively represent white noise exogenous demand and supply shocks, ${ }^{6}$ and $\phi_{\pi}$ and $\phi_{y}$ respectively capture the central bank's response to deviations of actual inflation from its target $\pi^{T}$, and to deviations of current output from its potential level. We realistically assume that the reaction function of the central bank respects the Taylor principle: in an IT regime, the weight attributed to inflation stabilization is more important.

In the New Keynesian framework, agents have to forecast both inflation and the output gap. However, following Cornand and M'baye (2016), we consider only inflation forecasts ${ }^{7}$ and make the assumption of naive expectations on the output gap, that is the expected output gap is equal to the lagged output gap $\left(\bar{y}_{t+1}^{e}=y_{t-1}\right)$. Although such an assumption may reinforce inertial expectations, there is significant evidence pointing to naive expectations. $^{8}$

Substituting equation (3) into (1), delivers:

$$
\begin{gathered}
y_{t}=\frac{1}{1+\alpha \phi_{y}} y_{t-1}-\frac{\alpha \phi_{\pi}}{1+\alpha \phi_{y}} \pi_{t}+\frac{\alpha}{1+\alpha \phi_{y}} \bar{\pi}_{t+1}^{e}+\frac{\alpha\left(\phi_{\pi}-1\right)}{1+\alpha \phi_{y}} \pi^{T}+\frac{1}{1+\alpha \phi_{y}} g_{t}, \\
\pi_{t}=\beta \bar{\pi}_{t+1}^{e}+\lambda y_{t}+u_{t},
\end{gathered}
$$

\footnotetext{
${ }^{6}$ As in Assenza et al. (2013), the fundamental shocks considered here are i.i.d. white noises. Instead, Pfajfar and Zakelj $(2013,2014)$ assume an AR(1) noise process, which implies that potential fluctuations in inflation are endogenously driven by agents' expectations.

${ }^{7}$ In contrast to Kryvtsov and Petersen (2013) or Arifovic and Petersen (2015), we ask for inflation expectations only (and not for output gap expectations). As that of Pfajfar and Zakelj (2013, 2014) and Assenza et al. (2013), our set-up presents the drawback to be less exhaustive in this respect but has the advantage to ask subjects for an easier task.

${ }^{8}$ Both survey papers (e.g. Pesaran and Weale (2006), Andolfatto et al. (2008), Lanne et al. (2009), Coibion and Gorodnichenko (2015)) and the LtFE literature (e.g. Hommes et al. (2005), Assenza et al. (2013), Pfajfar and Zakelj (2014), and Petersen (2014)) show that subjects' inflation expectations fail to be captured by rational expectations, but instead are well described by simple strategies, such as naive expectations.
} 
which yields:

$$
\pi_{t}=A+\frac{\alpha \lambda+\beta\left(1+\alpha \phi_{y}\right)}{1+\alpha\left(\phi_{y}+\lambda \phi_{\pi}\right)} \bar{\pi}_{t+1}^{e}+\frac{\lambda}{1+\alpha\left(\phi_{y}+\lambda \phi_{\pi}\right)} y_{t-1}+\varepsilon_{t}
$$

where $A=\frac{\alpha \lambda \pi^{T}\left(\phi_{\pi}-1\right)}{1+\alpha\left(\phi_{y}+\lambda \phi_{\pi}\right)}$ is a constant, and $\varepsilon_{t}=\frac{\lambda}{1+\alpha\left(\phi_{y}+\lambda \phi_{\pi}\right)} g_{t}+\frac{1+\alpha \phi_{y}}{1+\alpha\left(\phi_{y}+\lambda \phi_{\pi}\right)} u_{t}$ is the set of exogenous shocks.

\section{The experiment}

Following the LtFE literature, the experiment consists in asking subjects for inflation expectations, which are then put back into the model yielding economic outcomes. ${ }^{9}$ For experimental purpose, we calibrate the model parameters as Clarida et al. (2000): $\beta=$ 0.99, $\alpha=1$, and $\lambda=0.3$, and as in Cornand and M'baye (2016) we set the central bank's target value at $\pi^{T}=5$. This section presents the methodology, the procedure of our experiment, and provides a theoretical benchmark.

\subsection{Methodology}

As already explained, the experiment consists in asking subjects for their inflation expectations in the lab, and introducing them into the model presented in Section 2, which allows to compute, period after period, the values of the main macroeconomic variables (inflation, output gap, and interest rate).

Our main objective is to evaluate the macroeconomic performances of point versus band IT according to the strength of the shocks affecting the economy. We thus consider four different treatments in which subjects' task is to forecast next period inflation at each of the 60 periods of a session:

- Treatment 1 - Band targeting with small shocks: the central bank simply announces a band inflation target (which consists in the interval $[4 \%-6 \%]$ ) to the public, in a context where shocks have a variance of 0.08 .

- Treatment 2 - Point targeting with small shocks: the central bank explicitly communicates its $5 \%$ numerical target with a tolerance band of $+/-1 \%$ around its target in a context where the variance of shocks is 0.08 (same variance as in Treatment 1).

- Treatment 3 - Band targeting with large shocks: the central bank simply announces the band inflation target $([4 \%-6 \%])$ to the public (as in Treatment 1 ), but in a

\footnotetext{
${ }^{9}$ Our experimental framework is close to Pfajfar and Zakelj $(2013,2014)$ and Assenza et al. (2013), as we use the same model and the results come from agents' inflation expectations. However, our study differs from theirs in at least two respects. First, while these papers focus on the interplay between agents' inflation expectations formation process and monetary policy, our analysis focuses more precisely on the role of the announced point and band inflation target on agents' inflation expectations and on macroeconomic outcomes. Second, the reaction function of the central bank is also different: Pfajfar and Zakelj (2013, 2014) and Assenza et al. (2013) assume that the central bank only cares about inflation stabilization, while we more realistically assume that the central bank additionally takes into account (but with less weight) output gap stabilization.
} 
context where the variance of shocks is 0.5 .

- Treatment 4 - Point targeting with large shocks: the central bank explicitly communicates its $5 \%$ numerical target with a tolerance band of $+/-1 \%$ around its target (as in Treatment 2), but in a context where the variance of shocks is 0.5 (same variance as in Treatment 3 ).

Four sessions with 6 subjects each were conducted for each treatment, yielding 4 independent observations per treatment, as stated in Table 1.

\begin{tabular}{|c|c|c|c|c|c|}
\hline Treatment & $\phi_{\pi}$ & $\phi_{y}$ & Nb. of sessions (obs.) & Variance of shocks & Announcement \\
\hline 1 & 1.5 & 0.5 & 4 & 0.08 & band $[4 \%-6 \%]$ \\
\hline 2 & 1.5 & 0.5 & 4 & 0.08 & band $[4 \%-6 \%]$ and point $5 \%$ \\
\hline 3 & 1.5 & 0.5 & 4 & 0.5 & band $[4 \%-6 \%]$ \\
\hline 4 & 1.5 & 0.5 & 4 & 0.5 & band $[4 \%-6 \%]$ and point $5 \%$ \\
\hline
\end{tabular}

Table 1: Summary of sessions

\subsection{Procedure}

The experiment was run at the GATE-LSE laboratory (University of Lyon). Most subjects were undergraduate students from engineering and business administration. Participants earned about $€ 15$ on average depending on the accuracy of their forecasts. Sessions lasted about 45 minutes. ${ }^{10}$

At the beginning of each session, subject were given written instructions ${ }^{11}$ describing the economy, which was depicted by four main macroeconomic variables : inflation, output gap, interest rate and the central bank's point or band inflation target, and presenting to participants their role as forecasters in the economy. Subjects were informed about the fact that a point or band IT regime was implemented by the central bank in an environment subject to shocks. In all treatments, the economy began with initial values for inflation, output gap and interest rate of zero to ease treatment comparisons. While participants were not informed about the true model underlying the economy, they could observe on their screen time series of these variables up to the current period. They knew that the actual values of inflation and output gap mainly depended on their own predictions, as well as those of other subjects and that these macroeconomic outcomes depended on the lagged output gap, on random shocks that affected the economy, and on the central bank's inflation target. For comparison purpose, the small shocks treatments (Treatments 1 and 2 ) on the one hand, and the large shocks treatments (Treatments 3 and 4) on the other hand respectively implemented the same random shocks.

Participants' payoff function was given by: $\max \left\{\frac{160}{1+f}-40,0\right\}$, where $f=\mid \pi_{t}-$ $\pi_{t / t-1}^{i} \mid$ denoted the absolute value of the forecasting errors made by subject $i$, and was

\footnotetext{
${ }^{10}$ The program was written using z-Tree (Fischbacher, 2007).

${ }^{11}$ Appendix E provides a translation from French to English of instructions. Appendix F shows some examples of the screens.
} 
expressed in percentage points. This payoff function is such that a subject $i$ gets some points whenever its forecasting error is below $3 \%$ and the smaller this forecasting error, the higher the payoff.

\subsection{Theoretical predictions}

In a LtFE, subjects do not know the model of the economy but are only familiarized with a qualitative description of how the economy works. Therefore, and as already observed in many experiments, we do not expect subjects to form rational expectations. To account for the role of communicating the point target, we thus provide a theoretical benchmark based on a homogenous forecasting heuristics that includes the target and a naive component. ${ }^{12}$ For simulations purpose, the specific form given to this forecasting heuristic is: $\pi_{t+2 \mid t}^{i}=q \pi^{T}+(1-q) \pi_{t-1}$, which is inspired from Bomfin and Rudebusch (2000).

Figure 1 presents simulations results for output gap, inflation, and interest rates, setting (as in the experiment) initial values to zero for both strength of shocks (small ones on the left panels; large ones on the right panels). The solid line depicts the macroeconomic outcome for a forecasting heuristic that accounts for the communication of the point target ( $q=1$ in the simulations ${ }^{13}$ ), while the dashed line depicts the macroeconomic outcomes for a forecasting heuristic that does not account for the communication of the point target ( $q=0$ in the simulations). ${ }^{14}$

The comparison between the economic outcomes obtained with two different rules shows that macroeconomic variables converge more quickly to steady state values when the target is announced. This is especially true when the economy faces small shocks. Appendix A provides descriptive statistics showing that average levels of macroeconomic variables are much closer to steady state values ${ }^{15}$ and variances are much lower when the target is announced. In particular, with an announced target, inflation and interest rate are higher and the output gap is smaller than when the target is not announced.

So we conclude that in principle the announcement of the point target speads up convergence, slightly affects average levels and reduces the variance of macroeconomic outcomes, especially when the economy faces small shocks. In the case of large shocks, the effects are much less pronounced and even ambiguous.

\footnotetext{
${ }^{12}$ This rule represents only one example. One could do the same exercise with a rule including the target and adaptive or trend-extrapolative inflation expectations.

${ }^{13}$ Simulations with lower values of $q$ yield very similar trends.

${ }^{14}$ The latter rule is extreme in the sense that it does not account for the announcement of the band target. It therefore simply provides an idea on the direction of outcomes in comparison to a situation where the point target is communicated.

${ }^{15}$ The steady state is $\bar{y}=0.1, \bar{\pi}=4.8, \bar{i}=4.8$, which are close to target values.
} 

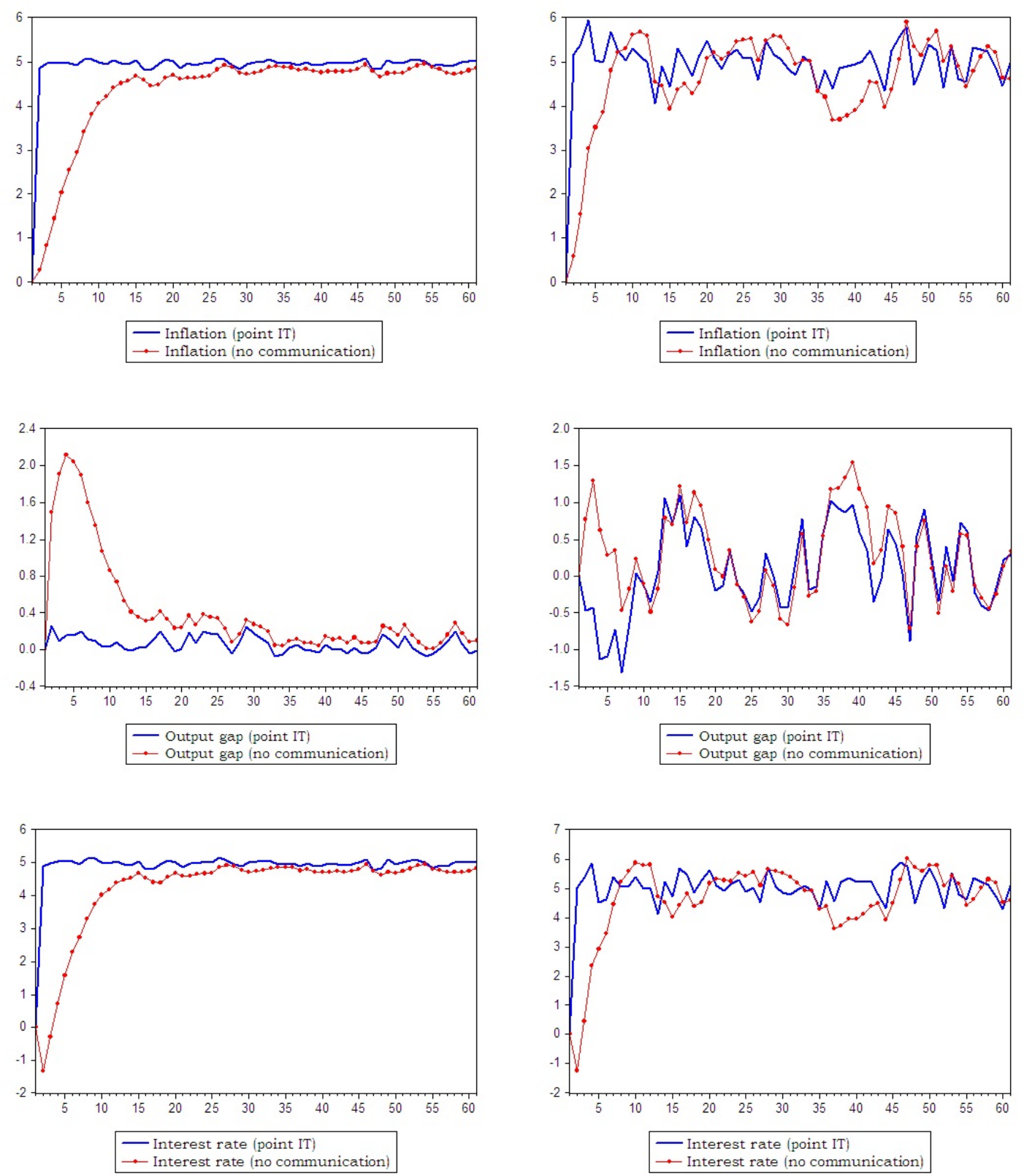

Figure 1: Inflation, output and interest rate with and without point target communication for small (left panels) and large (right panels) shocks

\section{Experimental economic outcomes}

We now analyze the macroeconomic outcomes of our experimental economy. ${ }^{16}$ Figure 2 presents the evolution of average inflation and inflation expectations across treatments. A graphical pairwise comparison shows that inflation and inflation expectations series exhibit similar patterns in Treatments 1 and 2 on the one hand, and in Treatments 3 and 4 on the other hand. Although both variables never go out of the inflation range of $4-6 \%$ from

\footnotetext{
${ }^{16}$ This section partly relies on individual expectation formation as described in Appendix G to explain macroeconomic results.
} 
the 5th period on in all treatments, we observe convergence towards the numerical point target when the economy is not subject to large shocks, and oscillations around the target in a context of large shocks.
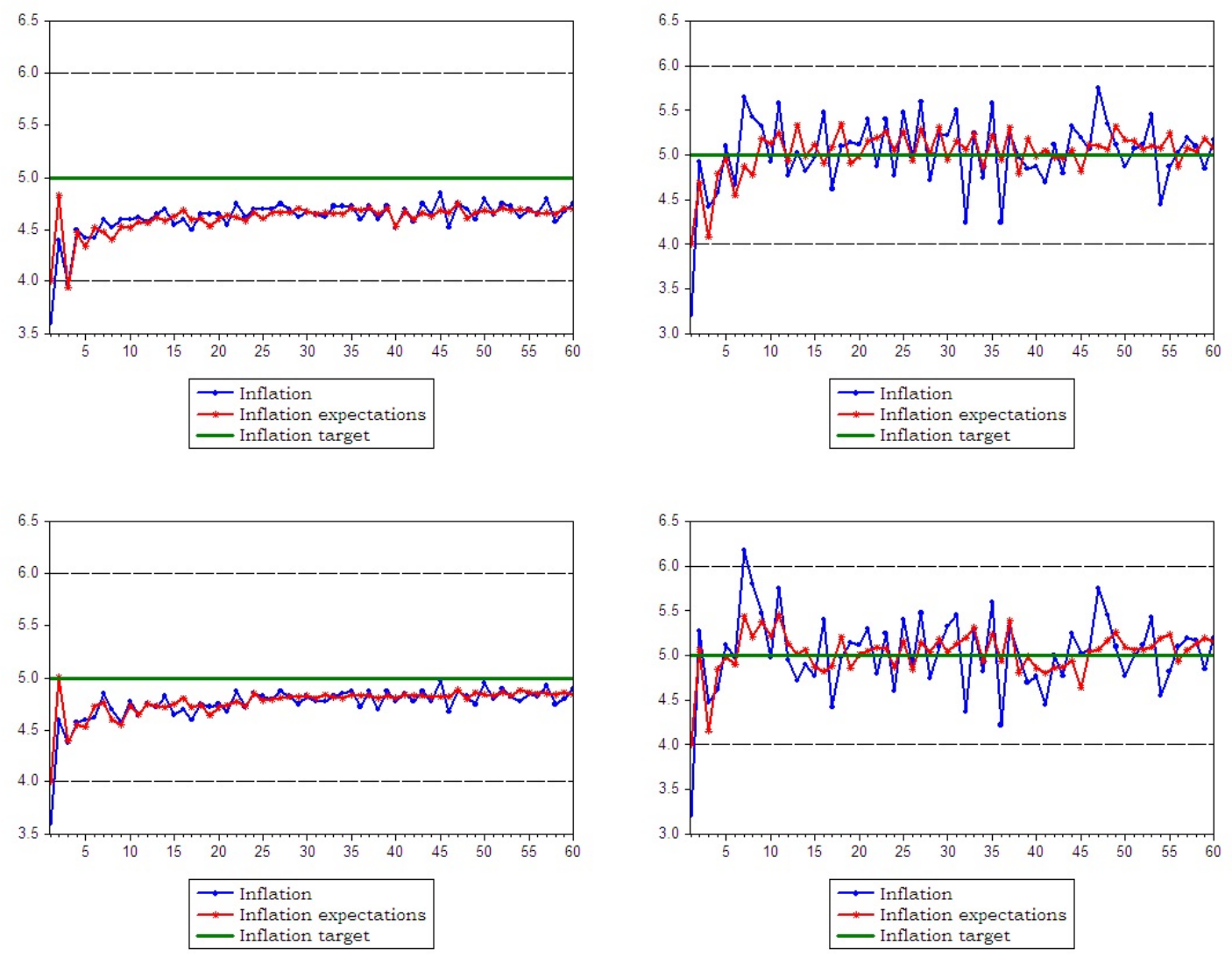

Figure 2: Average inflation and inflation expectations across treatments

In order to analyze whether explicitly announcing the numerical point target is relevant in terms of macroeconomic performance according to the economic environment, we perform a pairwise comparison between treatments, by using non-parametric statistical tests. ${ }^{17}$ We present the case of band versus point IT in a context of small shocks first, before analyzing the case of large shocks.

\subsection{Band vs. point IT: the case of small shocks}

Figure 3 depicts the evolution of average inflation and output gap series ${ }^{18}$ for band versus point IT (over 4 independent sessions for each treatment) when the macroeconomic environment is subject to small shocks. Inflation series exhibit quite similar trend-convergence although there is a faster convergence towards the numerical point target in Treatment

\footnotetext{
${ }^{17}$ The Mann-Whitney-Wilcoxon procedure is used to test for equality of medians between macroeconomic series of treatments, while Siegel-Tukey's test is used to assess whether there is a difference in terms of variances between series. The null hypothesis is that there is equality between series of interest in terms of medians or variances.

${ }^{18}$ Appendix D provides figures showing the evolution of inflation and average inflation expectations for each session of each treatment.
} 
2 (Point - low variance of shocks). Output gap series also present similar trends. Appendix $\mathrm{C}$ shows statistical tests regarding comparisons in macroeconomic outcomes series to capture differences between treatments.
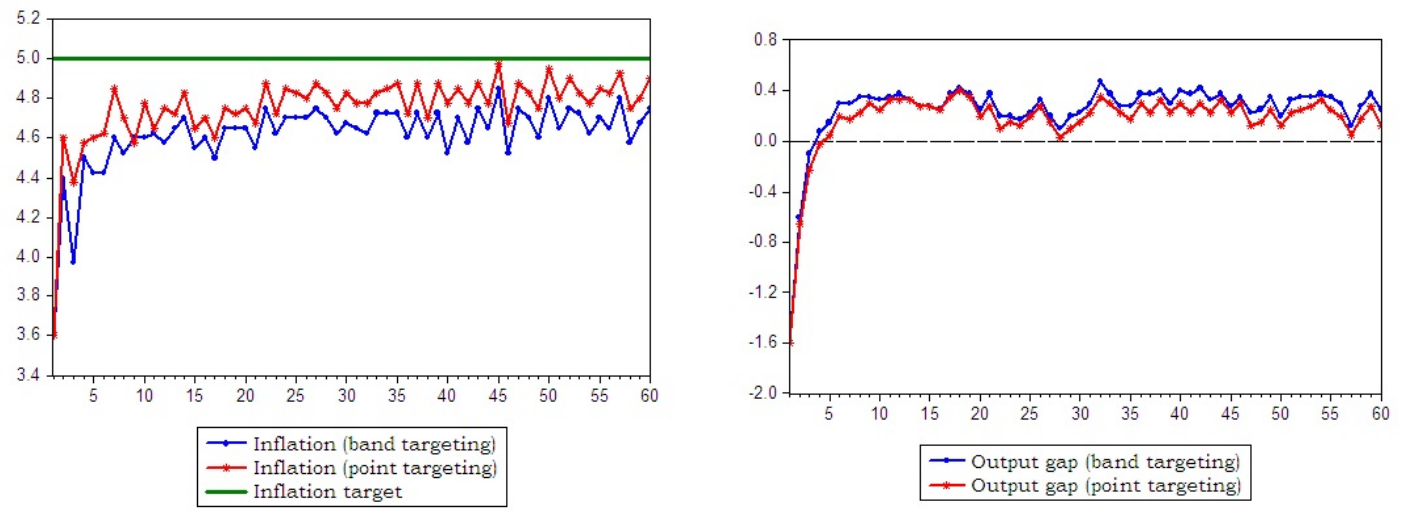

Figure 3: Average inflation and output gap series for band versus point IT with low variance of shocks

The statistical tests performed over 4 independent sessions for each treatment indicate that the average level of inflation is significantly higher in a point targeting regime with tolerance bands than in a band IT (4.78\% and $4.65 \%$ respectively). This observation can be explained by the faster and more important convergence towards the numerical target of $5 \%$ in the former regime. The announcement of the mid-point is thus relevant to insure faster convergence. However, the volatility of inflation is significantly lower in a band targeting regime than in a point targeting with tolerance bands. ${ }^{19}$ Both findings are consistent with theoretical predictions as developed in Section 3.3.

We find that the average level of output gap as well as its volatility are significantly lower in a point targeting regime with tolerance bands than in a band targeting regime. These results are also consistent with theoretical predictions as in Section 3.3.

Finally, concerning the interest rate, we find ambiguous results. Indeed, while its average level is significantly lower in a band targeting regime (contrasting with theoretical predictions), its volatility is on the contrary significantly lower in a point targeting regime with tolerance bands (in line with theoretical predictions).

We can summarize our findings as follows.

Result 1. When the economy is affected by small shocks, the average level of inflation as well as its volatility are significantly lower in a band targeting regime than in a point targeting regime with tolerance bands. The announcement effect of the mid-point target is however beneficial in terms of more rapid convergence towards the target. On the other hand, the average level of the output gap as well as the volatility of the output gap and interest rate are significantly lower in a point targeting regime with tolerance bands.

\footnotetext{
${ }^{19}$ See also Appendix B for the descriptive statistics of all treatments.
} 
Our analysis implies that when the economy faces small shocks, choosing the appropriate IT regime depends on the preference of the monetary authorities. If the latter are primarily interested in keeping inflation and its volatility low, then they should opt for a band IT. If in addition to the inflation stabilization objective, they wish to have a lower volatility of the output gap and interest rate, a point IT with a tolerance band seems preferable. The economic and financial stability would be reached in this case at the cost of temporarily higher inflation volatility.

Our findings stand in contrast to the literature. Indeed, according to Heenan et al. (2006), and Meyer (2002), a band IT provides more flexibility to the monetary authorities to smooth short-term variations in output at the expense of a temporarily higher volatility of inflation. Instead, we find that this beneficial effect of flexibility is more important in a point IT accompagnied by a tolerance band.

\subsection{Band vs. point IT: the case of large shocks}

Figure 4 presents the evolution of average inflation and output gap series for inflation band versus point targeting when the macroeconomic environment is subject to large shocks.
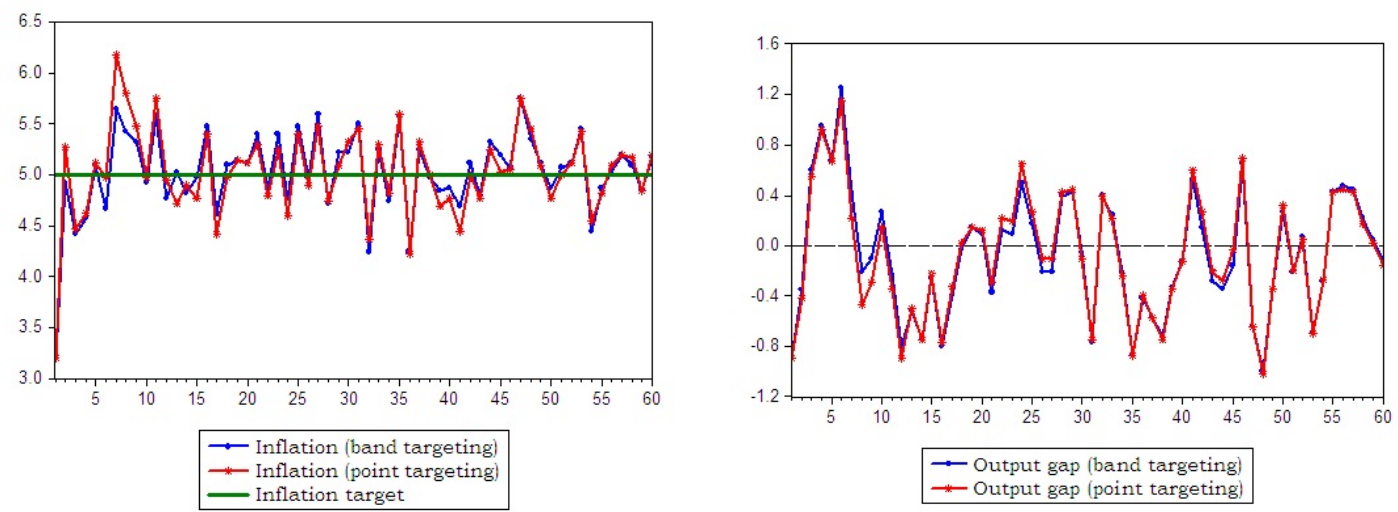

Figure 4: Average inflation and output gap series for band versus point IT with high variance of shocks

For both treatments, regarding both average inflation and output gap series, we observe similar trend-oscillations around the targets due to the higher variance of the shocks affecting the economy. Again, we recurse to statistical tests presented in Appendix C to check whether there are differences between both treatments in terms of macroeconomic outcomes series. Tests indicate that there are no significant differences at all conventional levels in terms of medians (or means) and variances of all macroeconomic outcomes between both regimes. These results are overall consistent with theoretical predictions as developed in Section 3.3.

The main implications of our analysis is that when the macroeconomic environment is subject to large shocks, the announcement of the numerical target does not make a difference. Two main reasons can be put forward to explain this result. The first explanation 
can be found in the irrelevance of the credibility issue in this environment. Indeed, the relatively weak control of the central bank over the macro-environment does not make a difference in terms of macroeconomic outcomes compared to the band targeting case. The second reason is related to the forecasting rules used by subjects. As explained in Appendix G, the trend extrapolation rule (the upward (downward) movements in inflation in the current period will be followed by the downward (upward) movements in the next period) better explains the evolution of average inflation expectations in all treatments. When the environment is subject to large shocks, the trend-extrapolating rule renders stabilization more complicated. Hence, the role of the announced target in this context is rather insignificant.

We can summarize our findings as follows.

Result 2. When the economic environment is subject to large shocks, the choice of the appropriate inflation targeting regime is irrelevant because the macroeconomic performance of both regimes is similar.

\section{Conclusion}

We analyze the rationale of adopting a band versus point IT, using laboratory experiments with human subjects. We implement a standard New Keynesian model in the lab to evaluate the macroeconomic performances of both IT regimes according to the strength of the shocks affecting the economy.

Overall, our results highlight that the choice of the appropriate IT regime depends on the macroeconomic environment, as well as on the preferences of the central bank. When the macroeconomic environment is subject to small shocks, choosing the appropriate IT regime depends on the preference of the monetary authorities. Indeed, if they are primarily interested in keeping inflation and its volatility low, then they should opt for an inflation band targeting. If, in addition to the inflation stabilization objective, they wish to have a lower volatility of the output gap and interest rate, a point IT with a tolerance band should be adopted. The economic and financial stability would be reached in this case at the cost of temporarily higher inflation volatility. However, when the macroeconomic environment is subject to large shocks, choosing the suitable IT regime is irrelevant because both regimes lead to comparable macroeconomic performances. While the applicability of experimental results outside the lab should be handled carefully, our study questions the relevance of clarifying a numerical point target within the bands especially in emerging market economies more inclined to large and frequent shocks. 


\section{References}

Andolfatto, D., Hendryand, S., and Moran, K. (2008). Are inflation expectations rational? Journal of Monetary Economics, 55:406-422.

Arifovic, J. and Petersen, L. (2015). Stabilizing expectations at the zero lower bound: Experimental evidence. Working Paper Department of Economics, Simon Fraser University.

Assenza, T., Heemeijer, P., Hommes, C., and Massaro, D. (2013). Individual expectations and aggregate macro behavior. Technical report, Tinbergen Institute Discussion Papers 13-016/II.

Barro, R. and Gordon, D. (1983). A positive theory of monetary policy in a natural rate model. Journal of Political Economy, 91:589-610.

Bernanke, B., Laubach, T., Mishkin, F., and Posen, A. (1999). Inflation targeting : Lessons from the international experience. Technical report, Princeton University Press.

Bomfin, A. and Rudebusch, G. (2000). Opportunistic and deliberate disinflation under imperfect credibility. Journal of Money, Credit and Banking, 32:707-721.

Calvo, G. and Mishkin, F. S. (2003). The mirage of exchange rate regimes for emerging market countries. Journal of Economic Perspectives, 17(4).

Clarida, R., Gali, J., and Gertler, M. (2000). Monetary policy rules and macroeconomic stability: Evidence and some theory. Quarterly Journal of Economics, 115(1):147-180.

Coibion, O. and Gorodnichenko, Y. (2015). Information rigidity and the expectations formation process: A simple framework and new facts. American Economic Review, 105:2644-2678.

Cornand, C. and M'baye, C. K. (2016). Does inflation targeting matter? an experimental investigation. Macroeconomic Dynamics, Forthcoming.

Fischbacher, U. (2007). z-tree: Zurich toolbox for ready-made economic experiments. Experimental Economics, 10(2):171-178.

Fraga, A., Goldfajn, I., and Minella, A. (2003). Inflation targeting in emerging market economies. Technical report, NBER Working Paper No. 10019.

Hammond, G. (2012). State of the Art of Inflation Targeting, chapter in: Handbooks. Number 29. Centre for Central Banking Studies, Bank of England.

Heenan, G., Peter, M., and Roger, S. (2006). Implementing inflation targeting: Institutional arrangements, target design, and communications. Technical report, IMF Working Paper/06/278. 
Hommes, C., Sonnemans, J., Tuinstra, J., and van de Velden, H. (2005). Coordination of expectations in asset pricing experiments. Review of Financial Studies, 18:955-980.

Kryvtsov, O. and Petersen, L. (2013). Expectations and monetary policy: Experimental evidence. Technical report, Department of Economics, Simon Fraser University, Discussion Papers series dp13-09.

Lanne, M., Luoma, A., and Luoto, J. (2009). A nave sticky information model of households inflation expectations. Journal of Economic Dynamics and Control, 33:1332-1344.

Levin, A., Natalucci, F., and Piger, J. (2004). The macroeconomic effects of inflation targeting. Federal Reserve Bank of St. Louis Review, 86(4):51-80.

Lin, S. and Ye, H. (2009). Does inflation targeting make a difference in developing countries? Journal of Development Economics, 89:118-123.

Meyer, L. (2002). Inflation targets and inflation targeting. The North American Journal of Economics and Finance, 13:147-162.

Mishkin, F. (2008). Whither federal reserve communications. Technical report, Remarks at the Peterson Institute for International Economics, Washington DC.

Mishkin, F. and Westelius, N. (2008). Inflation band targeting and optimal inflation contracts. Journal of Money, Credit and Banking, 40(4):557-582.

Mokhtarzadeh, F. and Petersen, L. (2016). Central bank communication and expectations. Working Paper Department of Economics, Simon Fraser University.

Orphanides, A. and Williams, J. C. (2007). Inflation Targeting under Imperfect Knowledge, volume Vol. XI, chapter In Frederic Mishkin and Klaus Schmidt-Hebbel (Ed), Monetary Policy Under Inflation Targeting. Banco central de Chile, Santiago, Chile.

Pesaran, M. and Weale, M. R. (2006). Survey expectations, pages 715-776.

Petersen, L. (2014). Forecast error information and heterogeneous expectations in Learning-to-Forecast macroeconomic Experiments, volume 17, pages 109-137.

Pfajfar, D. and Zakelj, B. (2013). Inflation expectations and monetary policy design: Evidence from the laboratory. Technical report, Tilburg University.

Pfajfar, D. and Zakelj, B. (2014). Experimental evidence on inflation expectation formation. Journal of Economic Dynamics and Control, 44:147-168.

Roger, S. (2009). Inflation targeting at 20 : Achievements and challenges. Technical report, IMF working paper 09/236, International Monetary Fund.

Roger, S. and Stone, M. (2005). On target? the international experience with achieving inflation targets. Technical report, IMF working paper No. 05/163, International Monetary Fund. 


\section{Appendix A: Theoretical predictions - Descriptive statistics}

\begin{tabular}{|c|c||c|c||c|c|}
\hline & \multicolumn{1}{|c||}{} & \multicolumn{2}{c||}{ small shocks } & \multicolumn{2}{c|}{ large shocks } \\
\hline & & Point IT & No communication & Point IT & No communication \\
\hline \multirow{3}{*}{ Mean } & Inflation & 4.80 & 4.31 & 4.89 & 4.62 \\
& Output & 0.11 & 0.40 & 0.11 & 0.28 \\
& Interest rate & 4.80 & 4.22 & 4.93 & 4.60 \\
\hline \multirow{3}{*}{ Variance } & Inflation & 0.51 & 1.28 & 0.66 & 1.22 \\
& Output & 0.03 & 0.29 & 0.34 & 0.35 \\
& Interest rate & 0.59 & 1.81 & 0.75 & 1.83 \\
\hline
\end{tabular}

\section{Appendix B: Experiment - Descriptive statistics}

\section{B.1. Band IT}

\begin{tabular}{|c|c|c|c|c|c|c|c|c|c|c|}
\hline \multicolumn{11}{|c|}{ Inflation expectations } \\
\hline \multirow[t]{2}{*}{ Stat. by session $(\mathrm{S})$} & \multicolumn{5}{|c|}{ BT with low variance of shocks } & \multicolumn{5}{|c|}{ BT with high variance of shocks } \\
\hline & S1 & $\mathrm{S} 2$ & S3 & S4 & Avg & $\mathrm{S} 1$ & $\mathrm{~S} 2$ & S3 & $\mathrm{S} 4$ & Avg \\
\hline Mean & 4.57 & 4.52 & 4.74 & 4.61 & 4.61 & 4.96 & 5.06 & 4.93 & 5.17 & 5.03 \\
\hline Median & 4.60 & 4.58 & 4.77 & 4.65 & 4.66 & 4.96 & 5.05 & 4.97 & 5.24 & 5.06 \\
\hline SdtDev & 0.12 & 0.17 & 0.21 & 0.16 & 0.15 & 0.42 & 0.26 & 0.21 & 0.33 & 0.25 \\
\hline \multicolumn{11}{|c|}{ Inflation } \\
\hline \multirow[t]{2}{*}{ Stat. by session $(\mathrm{S})$} & \multicolumn{5}{|c|}{ BT with low variance of shocks } & \multicolumn{5}{|c|}{ BT with high variance of shocks } \\
\hline & S1 & $\mathrm{S} 2$ & S3 & S4 & Avg & $\mathrm{S} 1$ & $\mathrm{~S} 2$ & $\mathrm{~S} 3$ & $\mathrm{~S} 4$ & Avg \\
\hline Mean & 4.58 & 4.54 & 4.72 & 4.62 & 4.62 & 4.96 & 5.06 & 4.94 & 5.15 & 5.03 \\
\hline Median & 4.60 & 4.60 & 4.80 & 4.70 & 4.65 & 5 & 5.10 & 5 & 5.20 & 5.09 \\
\hline SdtDev & 0.18 & 0.20 & 0.23 & 0.20 & 0.18 & 0.51 & 0.43 & 0.41 & 0.45 & 0.42 \\
\hline \multicolumn{11}{|c|}{ Output gap } \\
\hline \multirow[t]{2}{*}{ Stat. by session $(\mathrm{S})$} & \multicolumn{5}{|c|}{ BT with low variance of shocks } & \multicolumn{5}{|c|}{ BT with high variance of shocks } \\
\hline & S1 & $\mathrm{S} 2$ & S3 & $\mathrm{S} 4$ & Avg & S1 & $\mathrm{S} 2$ & S3 & $\mathrm{S} 4$ & Avg \\
\hline Mean & 0.29 & 0.29 & 0.17 & 0.24 & 0.25 & -0.03 & -0.09 & -0.01 & -0.14 & -0.07 \\
\hline Median & 0.35 & 0.35 & 0.20 & 0.30 & 0.30 & -0.05 & -0.10 & -0.05 & -0.20 & -0.13 \\
\hline SdtDev & 0.29 & 0.30 & 0.28 & 0.29 & 0.29 & 0.52 & 0.47 & 0.48 & 0.51 & 0.49 \\
\hline \multicolumn{11}{|c|}{ Interest rate } \\
\hline \multirow[t]{2}{*}{ Stat. by session $(\mathrm{S})$} & \multicolumn{5}{|c|}{ BT with low variance of shocks } & \multicolumn{5}{|c|}{ BT with high variance of shocks } \\
\hline & S1 & $\mathrm{S} 2$ & S3 & $\mathrm{S} 4$ & Avg & S1 & $\mathrm{S} 2$ & S3 & $\mathrm{S} 4$ & Avg \\
\hline Mean & 4.55 & 4.48 & 4.69 & 4.57 & 4.57 & 4.96 & 5.06 & 4.93 & 5.17 & 5.03 \\
\hline Median & 4.60 & 4.60 & 4.80 & 4.70 & 4.65 & 5 & 5.20 & 5 & 5.30 & 5.14 \\
\hline SdtDev & 0.38 & 0.41 & 0.44 & 0.42 & 0.40 & 0.74 & 0.67 & 0.63 & 0.66 & 0.63 \\
\hline
\end{tabular}




\section{B.2. Point IT}

\begin{tabular}{|c|c|c|c|c|c|c|c|c|c|c|}
\hline \multicolumn{11}{|c|}{ Inflation expectations } \\
\hline \multirow[t]{2}{*}{ Stat. by session (S) } & \multicolumn{5}{|c|}{ PT with low variance of shocks } & \multicolumn{5}{|c|}{ PT with high variance of shocks } \\
\hline & $\mathrm{S} 1$ & $\mathrm{~S} 2$ & S3 & S4 & Avg & S1 & S2 & S3 & S4 & Avg \\
\hline Mean & 4.83 & 4.31 & 5.05 & 4.89 & 4.77 & 4.95 & 5.18 & 4.89 & 5.09 & 5.03 \\
\hline Median & 4.84 & 4.52 & 5 & 4.92 & 4.81 & 5.03 & 5.16 & 4.93 & 5.09 & 5.07 \\
\hline SdtDev & 0.16 & 0.43 & 0.23 & 0.17 & 0.14 & 0.28 & 0.51 & 0.24 & 0.24 & 0.25 \\
\hline \multicolumn{11}{|c|}{ Inflation } \\
\hline \multirow[t]{2}{*}{ Stat. by session $(\mathrm{S})$} & \multicolumn{5}{|c|}{ PT with low variance of shocks } & \multicolumn{5}{|c|}{ PT with high variance of shocks } \\
\hline & $\mathrm{S} 1$ & $\mathrm{~S} 2$ & S3 & S4 & Avg & S1 & S2 & S3 & S4 & Avg \\
\hline Mean & 4.80 & 4.37 & 4.99 & 4.85 & 4.75 & 4.97 & 5.16 & 4.91 & 5.08 & 5.03 \\
\hline Median & 4.80 & 4.50 & 5 & 4.90 & 4.78 & 5 & 5.15 & 5 & 5.10 & 5.04 \\
\hline SdtDev & 0.19 & 0.39 & 0.25 & 0.22 & 0.19 & 0.44 & 0.64 & 0.42 & 0.43 & 0.45 \\
\hline \multicolumn{11}{|c|}{ Output gap } \\
\hline \multirow[t]{2}{*}{ Stat. by session (S) } & \multicolumn{5}{|c|}{ PT with low variance of shocks } & \multicolumn{5}{|c|}{ PT with high variance of shocks } \\
\hline & $\mathrm{S} 1$ & $\mathrm{~S} 2$ & S3 & $\mathrm{S} 4$ & Avg & S1 & S2 & S3 & S4 & Avg \\
\hline Mean & 0.15 & 0.39 & 0.02 & 0.14 & 0.17 & -0.03 & -0.16 & -0.01 & -0.09 & -0.07 \\
\hline Median & 0.20 & 0.40 & 0.10 & 0.20 & 0.23 & -0.10 & -0.15 & -0.05 & -0.10 & -0.10 \\
\hline SdtDev & 0.29 & 0.35 & 0.29 & 0.27 & 0.28 & 0.49 & 0.56 & 0.50 & 0.47 & 0.49 \\
\hline \multicolumn{11}{|c|}{ Interest rate } \\
\hline \multirow[t]{2}{*}{ Stat. by session $(\mathrm{S})$} & \multicolumn{5}{|c|}{ PT with low variance of shocks } & \multicolumn{5}{|c|}{ PT with high variance of shocks } \\
\hline & $\mathrm{S} 1$ & $\mathrm{~S} 2$ & S3 & $\mathrm{S} 4$ & Avg & S1 & $\mathrm{S} 2$ & S3 & $\mathrm{S} 4$ & Avg \\
\hline Mean & 4.80 & 4.27 & 4.99 & 4.86 & 4.73 & 4.96 & 5.19 & 4.89 & 5.09 & 5.03 \\
\hline Median & 4.90 & 4.50 & 5 & 4.95 & 4.83 & 5.10 & 5.25 & 5 & 5.20 & 5.16 \\
\hline SdtDev & 0.39 & 0.59 & 0.44 & 0.43 & 0.39 & 0.68 & 0.92 & 0.65 & 0.67 & 0.68 \\
\hline
\end{tabular}




\section{Appendix C: Statistical tests results}

In the following tables, p-values are reported in brackets. ***, ** and * respectively indicate significance at $1 \%, 5 \%$ and $10 \%$ conventional levels.

C.1. Pairwise comparison: band versus point IT with low variance of shocks

\begin{tabular}{|c|c|c|}
\hline & Mann-Whitney-Wilcoxon test & Siegel-Tukey test \\
\hline Macroeconomic outcomes & Statistical equality of medians? & Statistical equality of variances? \\
\hline Inflation & $\mathrm{No}^{* * *}(0.0001)$ & $\mathrm{No}^{*}(0.0566)$ \\
\hline Output gap & $\mathrm{No}^{* * *}(0.0010)$ & $\mathrm{No}^{*}(0.0879)$ \\
\hline Interest rate & $\mathrm{No}^{* * *}(0.0001)$ & $\mathrm{No}^{* *}(0.0118)$ \\
\hline
\end{tabular}

C.2. Pairwise comparison: band versus point IT with high variance of shocks

\begin{tabular}{|c|c|c|}
\hline & Mann-Whitney-Wilcoxon test & Siegel-Tukey test \\
\hline Macroeconomic outcomes & Statistical equality of medians? & Statistical equality of variances? \\
\hline Inflation & Yes $(0.8583)$ & Yes $(0.6785)$ \\
\hline Output gap & Yes $(0.9958)$ & Yes $(0.7709)$ \\
\hline Interest rate & Yes $(0.8914)$ & Yes $(0.5868)$ \\
\hline
\end{tabular}




\section{Appendix D: Average inflation and inflation expectations se- ries across sessions by treatment}
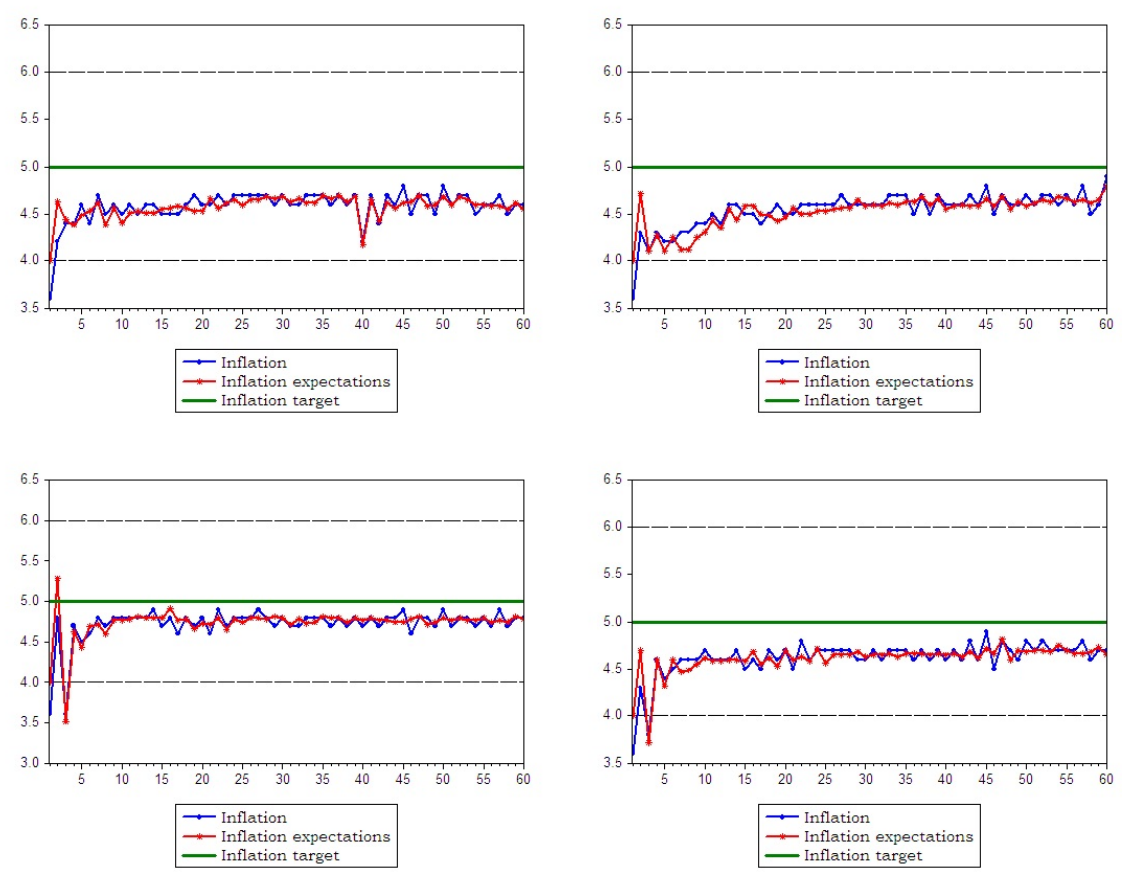

Figure 5: Average inflation and inflation expectations under band IT with low variance of shocks for 4 different sessions
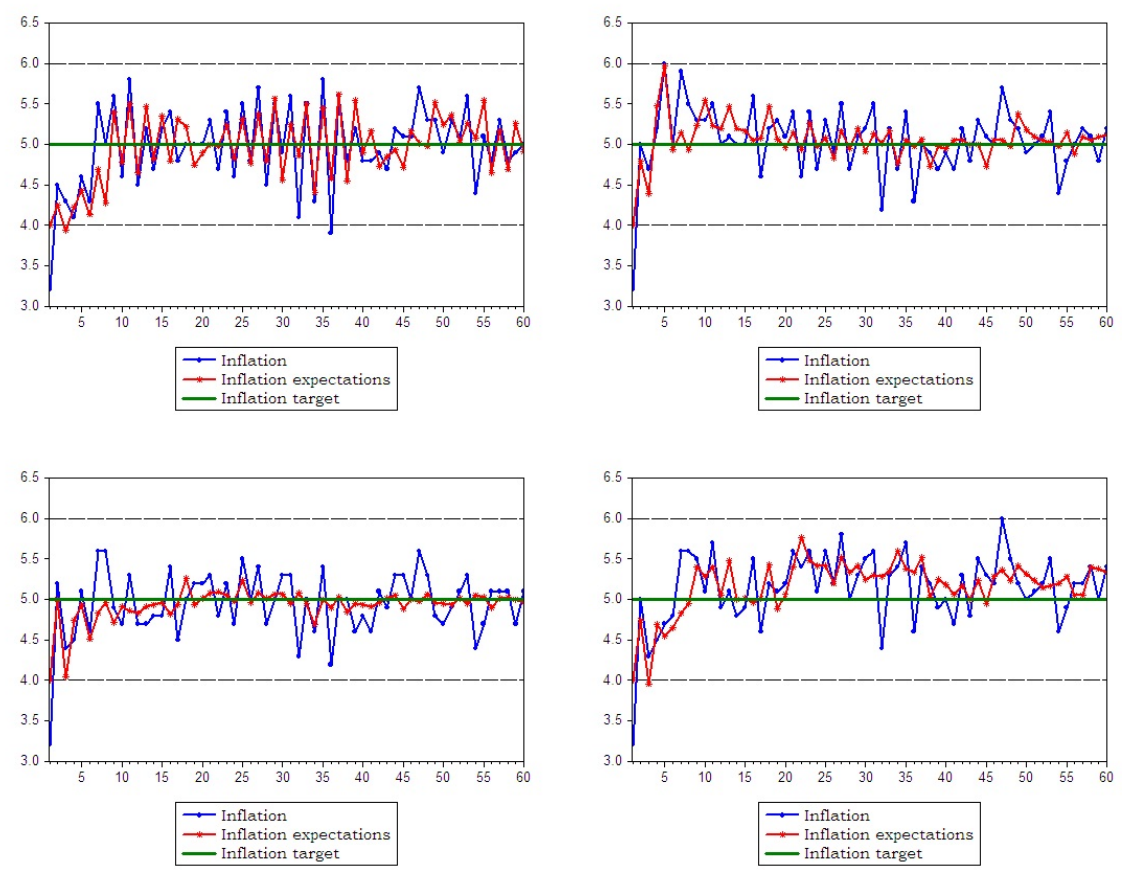

Figure 6: Average inflation and inflation expectations under band IT with large variance of shocks for 4 different sessions 

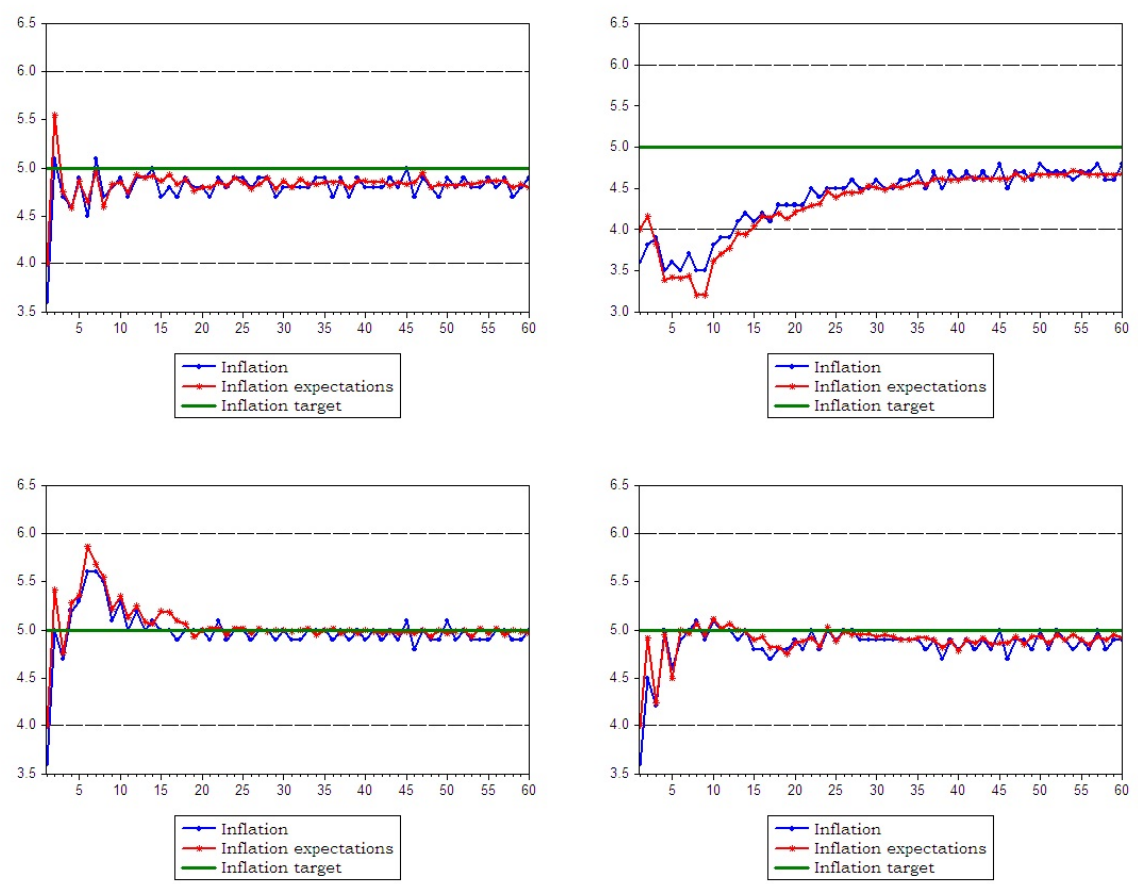

Figure 7: Average inflation and inflation expectations under point IT with low variance of shocks for 4 different sessions
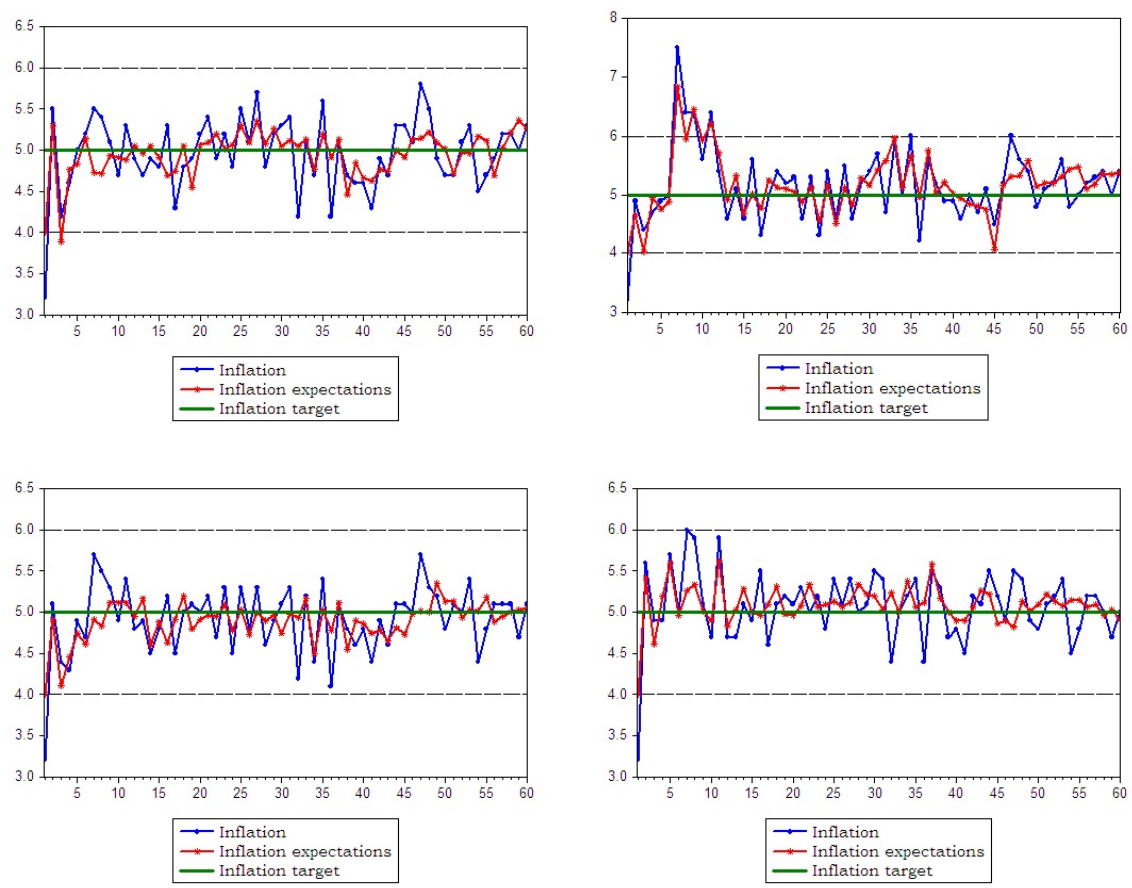

Figure 8: Average inflation and inflation expectations under point IT with large variance of shocks for 4 different sessions 


\section{Appendix E: Instructions}

We present a translation from French to English of the instructions for inflation point targeting treatments. Instructions for other treatments are available from the authors upon request.

\section{General information}

Thank you for your participation to this economic experiment in which you can earn money. Your earnings will depend on both your actions and those of the other participants and will be paid in cash at the end of the experiment. From now until the end of the experiment, you are not allowed to communicate with each other. If you have any question, please raise your hand and we will come to you.

You are a group of 6 participants. The rules are the same for all participants. The experiment consists of 60 periods. Your role is to predict future values of a given economic variable. Your earnings will depend on the accuracy of your predictions. At each of the 60 periods, the economy will be characterized by the following variables: the inflation rate, the output gap, the interest rate, and the inflation target of the central bank.

\section{Information about economic variables}

To better understand the economic variables that you will use to make your decisions, we explain these variables as follows.

Inflation: is defined as the generalized rise in prices in the economy. Inflation will depend in each period on agents' average inflation forecasts in the economy (that is, both your forecast and the forecasts of the 5 other participants), on the output gap, as well as on a random shock affecting the economy.

The output gap: describes the gap between the current output and the potential output (that is, the level of output the economy can achieve by using the maximum of its productive capacity). If the output gap is positive, the economy is producing beyond its potential level. Conversely, if the output gap is negative, the economy is producing below its potential level. The output gap also depends in each period on the agents' average inflation forecasts (your prediction and the predictions of the 5 other participants), the lagged output gap, the interest rate as well as a random shock affecting the economy.

The interest rate: is defined as the price of borrowing money for a period, and is set by the central bank of the economy. The interest rate mainly depends on inflation (and therefore indirectly on inflation forecasts), the output gap and the inflation target of the central bank.

The inflation target: is clearly announced to all participants by the central bank in the form of a numerical target of $5 \%$ with a tolerance interval of $+/-1 \%$ around the target. The announcement of the inflation target reflects the central bank's determination to guide current inflation towards its numerical target. So the central bank commits to reach its inflation target of $5 \%$. However, given the various random shocks affecting the economy, the central bank allows itself a margin error of $+/-1 \%$ around its target. The 
inflation target then corresponds to a commitment of the central bank which has to ensure (via the interest rate) that inflation in the economy will converge towards this target.

The central bank has two goals: one primary, and the other secondary.

The primary goal: the most important is for the central bank to stabilize inflation that is, to make as quickly as possible actual inflation converge towards its numerical target of $5 \%$. The central bank uses the interest rate to stabilize inflation. Positive and significant deviations of actual inflation from the target (that is, actual inflation is not equal to the numerical target of $5 \%$, and is above the upper band of the tolerance interval of $6 \%$ ), force the central bank to increase the interest rate in order to lead actual inflation towards its target. By contrast, when the central bank notes that inflation is too low compared to its inflation target (that is, actual inflation is not equal to the numerical target of $5 \%$, and is below the lower band of the tolerance interval of $4 \%$ ) and penalizes the economic activity, it reduces the interest rate.

The secondary goal consists for the central bank in stabilizing the output gap that is, the gap between the current and potential output of the economy, by also using the interest rate. When the output gap is positive, the central bank tends to increase the interest rate, and when it is negative, the central bank tends to reduce the interest rate.

All these variables can be relevant for your inflation forecasts, but it is up to you to use them in your convenience to decide on your inflation expectations. The actual values of the different variables largely depend on your inflation forecasts and those of the others, but also on random shocks affecting the economy.

At the beginning of the experiment and before entering your inflation forecast for the first period in the computer, you observe on the screen initial values of the main economic variables (inflation, output gap and interest rate) at period 0. As stated earlier, the central bank implements an inflation targeting strategy by announcing to all participants its numerical target of $5 \%$ with tolerance interval of $+/-1 \%$. By this announcement, the central bank commits to lead actual inflation towards its inflation target within a maximum of two periods. So you observe the central bank's target within its tolerance interval. This target remains unchanged throughout the duration of the experiment. Based on these variables, you have to forecast inflation for the next period.

Once you have made your decision, a period ends and a new period starts where you observe the past and actual values of inflation, the output gap, the interest rate, and your inflation forecast made in the previous period. However, you do not observe the expectations of other participants in your group (you just indirectly observe them through actual inflation). All you observe in terms of expectations is your own time series forecasts. As time goes on, you get a large number of observations that allows you to evaluate the accuracy of your forecasts compared to actual values of inflation, as well as the inflation target of the central bank.

\section{Information about your role in the economy}

Throughout the 60 periods of the experiment, your role as an agent of the economy is 
simple. You have to forecast the actual value of future inflation. In other words, you have to predict in each period, the inflation that will prevail in the next period based on all information available to you when making your decision. You must then enter in the computer your inflation forecast. Suppose that on your computer screen, you observe at period 2, actual inflation. This observed inflation is not based on the forecasts that you and the other participants of your group have made at period 2, but the predictions you made in the previous period that is, those made in period 1 for period 2 .

By choosing your inflation forecast, you seek to maximize your earnings. Your gain in each period depends on the accuracy of your inflation forecast relative to actual (realized) inflation. More specifically, your gain is given by:

$$
\text { Your profit in ECU }=\max \left\{\frac{160}{1+f}-40,0\right\} \text {, }
$$

where $f=\mid$ Inflation - Your forecast $\mid$. 'Inflation' indicates actual inflation, 'Your forecast' defines your inflation forecast made at previous period for the next, $f$ indicates in absolute value your forecasting error, and finally 'ECU' indicates the Experimental Currency Unit. The profit function above means that you get money every time your forecasting error is less than 3\%. The smaller your forecasting error, the higher your payoff. For instance if $f=0$, you receive the maximum payoff of 120 units $(160 /(1+0)-40)$. If your forecasting error is of $1.5 \%$, you receive 24 units $(160 /(1+1.5)-40)$. Otherwise if your forecasting error is of $3 \%$ or higher, then you receive 0 unit $(160 /(1+3)-40)$. You can only choose your inflation forecasts within the interval $[3,16]$. You can only choose whole numbers or numbers with one decimal digit (for instance, $5,8.5,4.6$, etc). In addition, when making your decisions, you have to enter only numbers without the "\%" symbol.

Once you have entered your decision in the computer, click on the 'Submit' button. Once all participants have done the same, the period ends and the profit for this period is written on the computer screen. Then, the next period starts. Once all the 60 periods are completed, the experiment ends. At each of the 60 periods of the experiment, at the top of each screen and on a graph, you can observe the entire history of economic variables as well as your earnings. You can then check at each period if your inflation forecast made in the previous period corresponds to actual inflation, and also whether it corresponds or converges towards the inflation target of the central bank. You will get informed about your gains period by period, and at the end of the experiment, your earnings will be added and will be paid in cash converted at the exchange rate of $€ 1=520$ ECU. Note that you do not get money in the first period of the experiment because you will not have made

any forecast for this period 1 . So your potential gains start at period 2 of the experiment, because you will have made forecasts at period 1 for this period 2 .

\section{Questionnaire}

At the beginning of the experiment, we ask you to fill out a questionnaire to make sure that you understand instructions. When all participants have correctly answered the ques- 
tionnaire, the experiment will begin. At the end of the experiment, we ask you to complete a personal questionnaire on the computer. All requested information will remain strictly confidential and is used for the sole purpose of research.

If you have any questions, please ask them now!

Thank you for your participation! 


\section{Appendix F: Examples of screens}

We provide examples of screens (first screen: band IT; second screen: point IT).
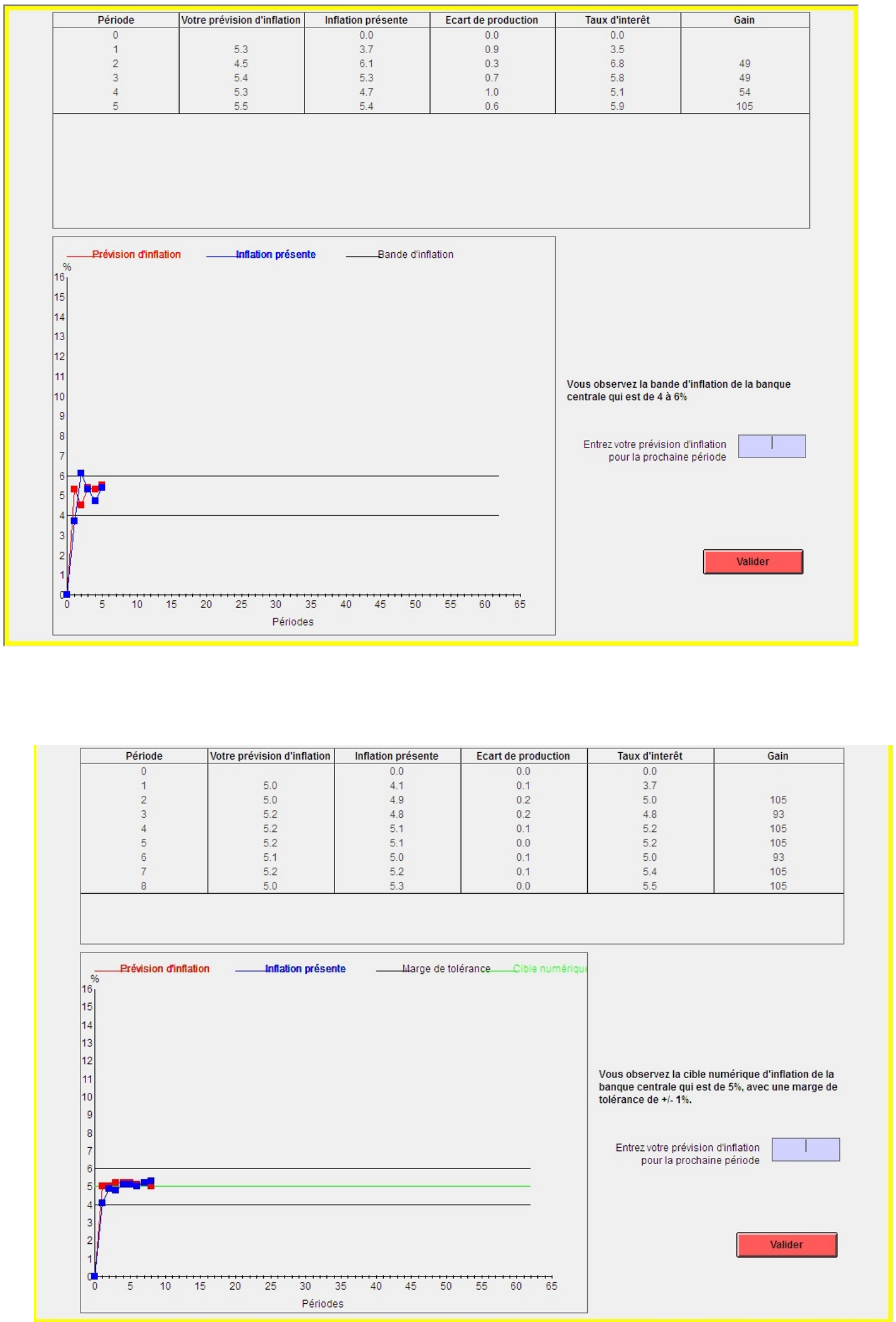


\section{Appendix G: Formation of individual inflation expectations}

Agents' expectations influence macroeconomic outcomes. Following the LtFE literature that emphasizes expectation heterogeneity, we study the formation of individual inflation expectations owing to the collected times series data for all subjects. This allows us to evaluate the impact of point versus band IT regimes on subjects' expectation formation process.

Following Pfajfar and Zakelj (2013, 2014), Assenza et al. (2013), and Cornand and M'baye (2016), we consider the main expectations formation models supported in the literature. We assume that subjects behave like econometricians and select both the given rule and its parameters to forecast inflation. We do not include exogenous shocks in the given expectation models, because they were not directly observable in the experiment. ${ }^{20}$ For each subject of each session (each including 4 treatments), we estimate the coefficient(s) of interest of the given expectation model (OLS estimation). Conditional on the significance of the estimated parameter(s), we then compute for each treatment the percentage of subjects using such and such forecasting rule.

\section{G.1. Prediction models}

Naive expectations model:

$$
\pi_{t+1 / t}^{i}=\alpha_{0}+\alpha_{1} \pi_{t-1}
$$

where $\pi_{t+1 / t}^{i}$ denotes subject $i$ 's (where $\left.i=1,2, \ldots, 96\right)$ inflation expectation made at time $t$ for $t+1, \pi_{t-1}$ represents the past period inflation rate, and $\alpha_{0}$ and $\alpha_{1}$ are the estimating parameters.

\section{AR(1) expectations model:}

$$
\pi_{t+1 / t}^{i}=\beta_{0}+\beta_{1} \pi_{t / t-1}^{i}
$$

where $\pi_{t+1 / t}^{i}$ denotes subject $i$ 's inflation expectation made at time $t$ for $t+1, \pi_{t / t-1}^{i}$ represents its past period forecast, and $\beta_{0}$ and $\beta_{1}$ are the estimating parameters.

\section{Trend extrapolation model:}

$$
\pi_{t+1 / t}^{i}=\gamma_{0}+\pi_{t-1}+\gamma_{1}\left(\pi_{t-1}-\pi_{t-2}\right)
$$

where $\gamma_{0}$ and $\gamma_{1}$ are the estimating parameters.

\footnotetext{
${ }^{20}$ We drop the first 10 periods of the experiment out of our regression samples. Indeed, as in Assenza et al. (2013), we assume that subjects need to have first a learning step before completely forming their forecasting rules.
} 


\section{Adaptive expectations model:}

$$
\pi_{t+1 / t}^{i}=\pi_{t-1 / t-2}^{i}+\eta\left(\pi_{t-1}-\pi_{t-1 / t-2}^{i}\right)
$$

where $\eta \geq 0$ is the constant gain parameter.

\section{G.2. Econometric results}

Table 2 presents for each treatment the percentage of subjects using the given expectations model.

\begin{tabular}{|c|c|c|c|c|}
\hline Model & $\begin{array}{c}\text { Band } \\
\text { low variance of shocks }\end{array}$ & $\begin{array}{c}\text { Point } \\
\text { low variance of shocks }\end{array}$ & $\begin{array}{c}\text { Band } \\
\text { high variance of shocks }\end{array}$ & $\begin{array}{c}\text { Point } \\
\text { high variance of shocks }\end{array}$ \\
\hline M1 & 87.50 & 66.67 & 75.00 & 79.17 \\
\hline M2 & 37.5 & 58.33 & 33.33 & 20.83 \\
\hline M3 & 70.83 & 87.5 & 87.5 & 70.83 \\
\hline M4 & 95.83 & 95.83 & 91.67 & 95.83 \\
\hline
\end{tabular}

Table 2: Percentage of subjects using M1, M2, M3 and M4 expectation models for each treatment

The relevance of subjects' forecasting rule depends on the considered treatment. We find that Treatment 1 (band targeting with small shocks) is the one which has the highest proportion $(87.5 \%)$ of subjects that use the naive expectations model (M1) to forecast inflation, while Treatment 2 (point targeting with small shocks) is associated with the lowest proportion $(66.67 \%$ ) of subjects that use this forecasting rule to form their expectations. We also explore whether the behavior of individual inflation expectations among treatments is consistent with the $\mathrm{AR}(1)$ model. We find that most subjects do not really use this forecasting rule to predict inflation. Finally, we find that both trend extrapolation (M3) and adaptive expectations (M4) prediction rules play an important role in the dynamics of inflation expectations formation as all subjects in each treatment use on average these models to forecast inflation. Treatments 2 and 3 are associated with the highest proportion (87.5\%) of subjects using M3, while Treatments 1, 2 and 4 are associated with the highest proportion of subjects using adaptive learning rule to predict inflation. These results are consistent with those of Assenza et al. (2013), Pfajfar and Zakelj (2014), and Cornand and M'baye (2016) who find that subjects most use M3 and M4 to form their expectations. Moreover, we find that for the trend extrapolation model, the significant coefficient $\gamma_{1}$ is below 0 for a large proportion of subjects in all treatments, which suggests that on average and in all treatments, subjects using this rule expect that the upward (downward) movements in inflation in the current period will be followed by the downward (upward) movements in the next period. ${ }^{21}$

\footnotetext{
${ }^{21}$ Note that in Table 2, the shares of each treatment do not add up to $100 \%$. This is explained by the fact that subjects switch between different rules during the experiment as supported by the literature. See e.g. Assenza et al. (2013), Pfajfar and Zakelj (2013, 2014), and Cornand and M'baye (2016).
} 
Let us finally look for the prediction model that best explains the formation of average inflation expectations within each treatment. To do so, for each session of each treatment, we consider average inflation expectations and look at all prediction models to select the one that yields the highest adjusted $R^{2}$. After doing so, we select the most relevant forecasting rule for a whole treatment. We find that the trend extrapolation rule appears to be the forecasting model which best explains the formation of average inflation expectations in all treatments. 